\title{
Evaluation of cerebrovascular hemodynamics in patients with idiopathic intracranial hypertension using transcranial Doppler
}

Mahmoud M. Allam¹, Hatem A. Almasry², Sandra M. Ahmed ${ }^{1}$, Youssuf G. Taha ${ }^{2^{*}}$ and Mohammed I. Oraby ${ }^{2}$

\begin{abstract}
Background: Idiopathic intracranial hypertension $(\mathrm{IIH})$ is a disorder of increased intracranial pressure without a clear cause and can have serious visual effects. Previous research work suggests that transcranial Doppler measurements of pulsatility index correlate accurately with elevated intracranial pressure.

Objective: To assess the cerebrovascular hemodynamic changes in patients with IIH using transcranial Doppler before and after lumbar puncture and CSF withdrawal.

Methods: An interventional study conducted on 40 patients (31 females and 9 males) fulfilling the modified Dandy criteria for diagnosis of idiopathic intracranial hypertension, MRI brain, and MRV was done to the patients. Lumbar puncture was done for all included patients to measure intracranial pressure and CSF withdrawal. Transcranial Doppler was performed for all included before and after lumbar puncture and CSF withdrawal and the following parameters were measured: peak systolic velocity (PSV), end diastolic velocity (EDV), resistivity index (RI), and pulsatility index (PI).

Results: Significant relation was found between grades of papilledema and PSV, RI, and PI ( $p$ value 0.012, 0.025, $0.016)$ but no significant relation was found between grades of papilledema and EDV (0.102). Significant changes occurred in parameters of TCD pre- and post-CSF withdrawal including PSV, EDV, and PI ( $p$ value $0.001,0.015,0.019$ ) denoting a significant change in cerebral hemodynamics after CSF withdrawal which denotes a decrease in intracranial pressure.
\end{abstract}

Conclusion: Increased intracranial pressure significantly affects cerebral blood flow. A normalization of transcranial Doppler parameters occurs following lowering of intracranial pressure through lumbar puncture and CSF withdrawal.

Keywords: IIH, TCD, PSV, EDV, PI, RI

\footnotetext{
* Correspondence: yousef9yousef@yahoo.com

${ }^{2}$ Neurology Department, Beni-Suef University, Beni-Suef 62511, Egypt

Full list of author information is available at the end of the article
}

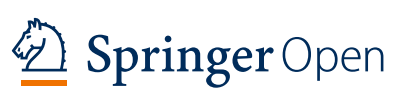

(c) The Author(s). 2020 Open Access This article is licensed under a Creative Commons Attribution 4.0 International License, which permits use, sharing, adaptation, distribution and reproduction in any medium or format, as long as you give appropriate credit to the original author(s) and the source, provide a link to the Creative Commons licence, and indicate if changes were made. The images or other third party material in this article are included in the article's Creative Commons licence, unless indicated otherwise in a credit line to the material. If material is not included in the article's Creative Commons licence and your intended use is not permitted by statutory regulation or exceeds the permitted use, you will need to obtain permission directly from the copyright holder. To view a copy of this licence, visit http://creativecommons.org/licenses/by/4.0/. 


\section{Introduction}

Idiopathic intracranial hypertension (IIH) is a neurological disorder characterized by increased intracranial pressure in the absence of a space occupying lesion or other diseases. The most common manifestations are headache, blurring of vision, pulsatile tinnitus, nausea, and vomiting. If not properly treated, it may progress to loss of vision [1].

Lumbar puncture is performed in patients with IIH to measure the opening cerebrospinal fluid (CSF) pressure and to exclude alternative diagnoses. CSF may be withdrawn for transient relief of symptoms if the opening pressure was too high [2].

The transcranial Doppler (TCD) and, recently, transcranial color-coded duplex (TCCD) are studies that can accurately measure the velocity of blood flow in cerebral blood vessels [3]. Previous studies demonstrated that transcranial Doppler measurements of pulsatility index correlate accurately with the degree of elevation in intracranial pressure (ICP) [4].

Both the pulsatility index (PI) and resistivity index (RI) indicate composite changes of vasoconstriction and vasodilatation in cerebral blood vessels [5]. The PI, firstly described by Gosling and King characterizes the shape of a spectral waveform [6]. The PI is suggested to reflect the degree of downstream vascular resistance. Lowresistance vascular beds have high diastolic flow with rounded waveforms and lower PIs. In contrast, higher resistance beds have low diastolic flow, a peaked waveform, and higher PIs [7]. PI is found to be significantly correlated with intracranial pressure [5]. Also, many studies have described the use of RI to study the relationship between cerebral perfusion pressure and intracranial pressure [8].

The aim of this work is to study the effect of increased intracranial pressure on cerebral blood flow and to assess cerebrovascular hemodynamic changes by using transcranial Doppler in patients with IIH before and after lumbar puncture.

\section{Methods}

This study is a cross sectional interventional study and included 40 idiopathic intracranial hypertension patients (31 patients $(77.5 \%)$ were females and 9 patients $(22.5 \%)$ were males). Our patient inclusion criteria were recurrent headache fulfilling the modified Dandy criteria according to Digre et al. [9] with bilateral papilledema provided normal brain imaging (CT and MRI-MRV of the brain) including patients on medical treatment of carbonic anhydrase inhibitors.

The following subjects were excluded: children younger than 16 years of age, patients with intracerebral tumors, patients with intracerebral vascular insults or large infection, patients with disturbed conscious level, patients with poor windows of TCD, pregnant female patients, and patients with comorbid headaches like ENT, infections, and errors of refraction.

A written informed consent was obtained from each participant in this study and the study was approved by the authorized ethical committee in Faculty of Medicine Cairo University Hospital Outpatient Neurology Clinic and Beni-Suef University Neurolgy Outpatient Clinic in 27 October 2013. Patients were recruited from the Faculty of Medicine Cairo University Hospital Outpatient Neurology Clinic and Beni-Suef University Neurolgy Outpatient Clinic.

Patients in this study were subjected to the following:

1. Thorough history taking with full analysis of headache and full neurological examination to ensure that they are fulfilling the modified Dandy criteria for diagnosis of idiopathic intracranial hypertension [10].

2. Full ophthalmological assessment: Visual acuity measurement was done using Snellen chart. Direct and indirect ophthalmoscopic fundus examination and the severity of papilledema was graded from grade 0 to 5 according to the Frisén staging scheme [11]. Visual field examination was done by automated perimetry; the field changes were graded from 0 to 4 according to Wall and George [12]. MRI brain with and without contrast and MRV were performed for patients on a 1.5-T Philips Intera Scanner, China, at the Magnetic Resonance Unit, Department of Radio-diagnosis, Cairo University.

3. Lumbar puncture: All patients underwent lumbar puncture under complete aseptic condition with the patient in the left lateral decubitus position with legs extended during pressure measurement. The opening pressure was measured by manometer. Twenty milliliters CSF were withdrawn to decrease the CSF pressure and samples were taken for analysis to ensure normal sugar, protein, chloride, and cell content.

4. Transcranial Doppler: This was done for all the included patients before and $10 \mathrm{~min}$ after withdrawal of CSF using Toshiba Xario 200, Japan, equipped by transcranial probe 2-5 MHZ. Middle cerebral arteries were insonated to obtain average values of the following parameters:

(a) Peak systolic velocity (PSV in $\mathrm{cm} / \mathrm{s}$ ): This is the first peak on a TCD waveform from each cardiac cycle. A rapid upstroke represents the absence of a severe stenotic lesion between the insonated intracranial arterial segment and heart. 
5. End-diastolic velocity (EDV in $\mathrm{cm} / \mathrm{s}$ ): The enddiastolic flow velocity (EDV) lies between 20 and $50 \%$ of the peak systolic velocity (PSV) values, indicating a low-resistance intracranial arterial flow pattern, seen in all major intracranial arteries.

6. Pulsatility index (PI): Flow resistance of the distal cerebral blood vessels and is usually calculated by subtracting EDV from PSV and dividing the value by MFV. This is the most frequently used TCD parameter to determine the flow resistance. PI is independent of the angle of insonation, has no unit, and a value more than 1.2 represents highresistance blood flow.

7. Resistivity index (RI): The RI is another TCD parameter sometimes used to assess the flow resistance. It represents flow resistance distal to the site of insonation. RI is calculated by subtracting EDV from PSV and dividing the value by PSV. Any value below 0.75 is normal.

Data were coded and entered using Microsoft Office Excel 2010. Statistical analysis was done using IBM SPSS version 24 (IBM Corporation, USA, Armonk, NY, 2016). Frequencies (number) and relative frequencies (percent) were used to summarize qualitative variables while mean and standard deviations were used for quantitative variables. Comparison between groups were done using ANOVA test followed by post hoc test for pairwise comparison between groups. Paired $t$ test was used to compare between TCD parameters before and after CSF withdrawal. $P$ value less than or equal to 0.05 was considered significant.

\section{Results}

This study included 40 patients with idiopathic intracranial hypertension. The age of patients ranged from 13 to 38 with a mean of $27 \pm 9$ years. Thirty-one patients were females (77.5\%) and nine patients were males (22.5\%) with female to male ratio 3.4:1. The duration of illness ranged from 25 to 34 months with the mean of $21.48+$ 12.32 months (duration determined from history taking of patients and archives of patients in Cairo University Hospital).

Table 1 demonstrates the main clinical presentations of the included patients. Headache and bilateral papilledema were found in $100 \%$ of the included patients.

We studied effects of papilledema grades on TCD parameters; a significant relation was found between grades of papilledema and PSV, RI, and PI but no significant relation was found between grades of papilledema and EDV which means that with higher grades of papilledema, PSV, RI, and PI show significant changes in cerebral blood flow more than EDV (Table 2).
Table 1 The main clinical presentations of the included patients

\begin{tabular}{|c|c|c|c|}
\hline & & \multicolumn{2}{|c|}{ Patients $(n=40)$} \\
\hline & & No. & $\%$ \\
\hline \multirow[t]{5}{*}{ Paplilledema grade } & Grade 1 & 7 & $17.5 \%$ \\
\hline & Grade 2 & 14 & $35.0 \%$ \\
\hline & Grade 3 & 9 & $22.5 \%$ \\
\hline & Grade 4 & 6 & $15 \%$ \\
\hline & Grade 5 & 4 & $10.0 \%$ \\
\hline \multirow[t]{3}{*}{ Visual symptoms } & Blurring of vision & 12 & $30.0 \%$ \\
\hline & Diplopia & 1 & $2.5 \%$ \\
\hline & TVOs & 27 & $67.5 \%$ \\
\hline \multirow[t]{3}{*}{ Visual acuity } & Normal & 20 & $50 \%$ \\
\hline & From $6 / 9$ to $6 / 60$ & 14 & $35 \%$ \\
\hline & Counting fingers & 6 & $15 \%$ \\
\hline \multirow[t]{5}{*}{ Perimetry } & Grade 0 & 3 & $7.5 \%$ \\
\hline & Grade 1 & 26 & $65.0 \%$ \\
\hline & Grade 2 & 5 & $12.5 \%$ \\
\hline & Grade 3 & 4 & $10.0 \%$ \\
\hline & Grade 4 & 2 & $5.0 \%$ \\
\hline \multirow[t]{2}{*}{ Headache frequency } & Daily and continuous & 22 & $55 \%$ \\
\hline & Irregular & 18 & $45 \%$ \\
\hline \multirow[t]{4}{*}{ Headache site } & Frontal & 6 & $15 \%$ \\
\hline & Bitemporal & 10 & $25 \%$ \\
\hline & Frontotemporal & 15 & $37.5 \%$ \\
\hline & Whole cranium & 9 & $22.5 \%$ \\
\hline \multirow[t]{2}{*}{ Headache character } & Bursting & 29 & $72.5 \%$ \\
\hline & Throbbing & 11 & $27.5 \%$ \\
\hline
\end{tabular}

TVOs transient visual obscurations

Regarding the results of lumbar puncture, the opening pressure in our patients ranged from 250 to $570 \mathrm{~mm} /$ $\mathrm{H}_{2} \mathrm{O}$ with a mean of $306.80 \pm 81.89$. CSF constituents were within normal levels in all patients (100\%). The patients were divided into 3 groups according to opening of CSF pressure: group 1 ranged from 250 to $350 \mathrm{~cm} /$ $\mathrm{H}_{2} \mathrm{O}$ (included 24 patients $(60 \%)$ ), group 2 ranged from 350 to $450 \mathrm{~cm} / \mathrm{H}_{2} \mathrm{O}$ (included 8 patients $(20 \%)$ ), and group 3 more than $450 \mathrm{~cm} / \mathrm{H}_{2} \mathrm{O}$ (included 8 patients $(20 \%))$.

Regarding the effect of CSF pressure on TCD parameters, there was a significant difference between the three groups regarding TCD parameters (PSV, EDV, RI, PI; Table 3).

Table 4 shows a comparison between TCD parameters pre- and post-CSF withdrawal; significant changes occurred in parameters of TCD including PSV-EDV-RI-PI denoting a significant change in cerebral hemodynamics after CSF withdrawal which denotes a decrease in intracranial pressure. 
Table 2 Comparison between grades of papilledema as regards TCD parameters

\begin{tabular}{|c|c|c|c|c|c|c|c|}
\hline & & Grade $1(n=7)$ & Grade $2(n=14)$ & Grade $3(n=9)$ & Grade $4(n=6)$ & Grade $5(n=4)$ & $p$ value \\
\hline \multirow[t]{3}{*}{ PSV } & Range & $78.8-87.3$ & $76.5-117.6$ & $94.8-119.81$ & $118.7-138.7$ & $132.6-141.1$ & $0.012^{*}$ \\
\hline & Mean & 81.7 & 90.8 & 101.9 & 132.4 & 136.5 & \\
\hline & $\pm S D$ & 3.8 & 10.1 & 90.1 & 7.7 & 3.7 & \\
\hline \multirow[t]{3}{*}{ EDV } & Range & $30-48.9$ & 24-49.5 & $27-42.6$ & $25.5-45.6$ & $24.7-28.8$ & 0.102 \\
\hline & Mean & 36.2 & 35.6 & 34.5 & 30.1 & 26.8 & \\
\hline & $\pm S D$ & 6.3 & 7.7 & 5.2 & 7.7 & 2.3 & \\
\hline \multirow[t]{3}{*}{$\mathrm{Rl}$} & Range & $0.4-0.7$ & $0.5-0.7$ & $0.6-0.7$ & $0.6-0.8$ & $0.8-0.8$ & $0.025^{*}$ \\
\hline & Mean & 0.6 & 0.6 & 0.7 & 0.8 & 0.8 & \\
\hline & $\pm \mathrm{SD}$ & 0.1 & 0.1 & 0.1 & 0.1 & 0.0 & \\
\hline \multirow[t]{3}{*}{$\mathrm{Pl}$} & Range & $0.5-1.0$ & $0.6-1.3$ & $0.8-1.2$ & $0.6-1.4$ & $1.3-1.4$ & $0.016^{*}$ \\
\hline & Mean & 0.8 & 0.9 & 1.0 & 1.1 & 1.3 & \\
\hline & $\pm S D$ & 0.1 & 0.2 & 0.1 & 0.3 & 0.1 & \\
\hline
\end{tabular}

${ }^{*} p$ value $<0.05$ (significant); PSV peak systolic velocity, EDV end diastolic velocity, PI pulsatility index, RI resistivity index, SD standard deviation

\section{Discussion}

Idiopathic intracranial hypertension previously named pseudotumor cerebri (PTC) was defined for the first time by Dandy as a syndrome characterized by symptoms and signs of raised intracranial pressure in absence of space occupying lesions, hydrocephalus, or infection in an otherwise alert and healthy patient [13].

Cerebral circulation is a dynamic state; the cerebral vasculature has complex regulatory systems that allow the brain to regulate its blood flow. The cerebral blood flow is dependent on the intracranial pressure; in a simplified statement, cerebral perfusion pressure is the difference between the mean arterial blood pressure and the intracranial pressure [14].

Transcranial Doppler sonographic imaging is a useful tool that could be implemented to assess the cerebral vasculature non-invasively. It is safe, inexpensive, and reliable when compared with other techniques. It can be repeated multiple times and can be used for continuous monitoring if needed [15].

The current study aimed to evaluate the cerebral blood flow in patients with idiopathic intracranial hypertension before and after CSF withdrawal by using transcranial Doppler measuring the following parameters: (peak systolic velocity-resistivity index-pulsatility index and end diastolic velocity) in middle cerebral artery [16].

In this study, we chose papilledema and CSF pressure as indicators for disease severity to demonstrate the relation between the degree of disease severity and cerebral blood flow. Bilateral papilledema was found in $100 \%$ of our patients. We divided the patients according to grade of papilledema into patients with papilledema grades grade $1=7$ patients, grade 2 $=14$ patients, grade $3=9$, grade $4=6$ patients, and finally grade $5=4$ patients. We found that there were statistically significant higher values of PSV and PI in

Table 3 Comparison between the 3 groups regarding TCD parameters

\begin{tabular}{|c|c|c|c|c|c|}
\hline & & Group $1\left(250-350 \mathrm{~cm} / \mathrm{H}_{2} \mathrm{O}\right)(n=24)$ & Group $2\left(350-450 \mathrm{~cm} / \mathrm{H}_{2} \mathrm{O}\right)(n=8)$ & Group $3\left(>450 \mathrm{~cm} / \mathrm{H}_{2} \mathrm{O}\right)(n=8)$ & $p$ value \\
\hline \multirow[t]{3}{*}{ PSV } & Range $(\mathrm{cm} / \mathrm{s})$ & $76.5-117.6$ & $94.8-137.6$ & $96.9-141.1$ & $0.001^{*}$ \\
\hline & Mean & 89.0 & 114.8 & 130.8 & \\
\hline & $\pm \mathrm{SD}(\mathrm{cm} / \mathrm{s})$ & \pm 9.5 & \pm 16.3 & \pm 14.3 & \\
\hline \multirow[t]{3}{*}{ EDV } & Range $(\mathrm{cm} / \mathrm{s})$ & $24.0-49.5$ & $26.9-45.6$ & $24.7-39.9$ & $0.029^{*}$ \\
\hline & Mean & 35.6 & 33.7 & 28.2 & \\
\hline & $\pm \mathrm{SD}(\mathrm{cm} / \mathrm{s})$ & \pm 6.7 & \pm 7.1 & \pm 5.0 & \\
\hline \multirow[t]{3}{*}{$\mathrm{Rl}$} & Range $(\mathrm{cm} / \mathrm{s})$ & $0.4-0.7$ & $0.6-0.8$ & $0.6-0.8$ & $0.001^{*}$ \\
\hline & Mean & 0.6 & 0.7 & 0.8 & \\
\hline & $\pm \mathrm{SD}(\mathrm{cm} / \mathrm{s})$ & \pm 0.1 & \pm 0.1 & \pm 0.1 & \\
\hline \multirow[t]{3}{*}{$\mathrm{Pl}$} & Range $(\mathrm{cm} / \mathrm{s})$ & $0.5-1.3$ & $0.9-1.4$ & $0.6-1.4$ & $0.005^{*}$ \\
\hline & Mean & 0.9 & 1.1 & 1.1 & \\
\hline & $\pm \mathrm{SD}(\mathrm{cm} / \mathrm{s})$ & \pm 0.2 & \pm 0.2 & \pm 0.3 & \\
\hline
\end{tabular}

" $p$ value < 0.05 (significant); PSV peak systolic velocity, EDV end diastolic velocity, $P$ p pulsatility index, $R /$ resistivity index, SD standard deviation 
Table 4 Comparison between TCD parameters pre- and post-CSF withdrawal

\begin{tabular}{lllll}
\hline & & Pre-CSF withdrawal $(\boldsymbol{n}=\mathbf{4 0})$ & Post-CSF withdrawal $(\boldsymbol{n}=\mathbf{4 0})$ & $\boldsymbol{p}$ value \\
\hline PSV & Range $(\mathrm{cm} / \mathrm{s})$ & $76.5-141.12$ & $56.89-112.6$ & $0.001^{*}$ \\
& Mean $(\mathrm{cm} / \mathrm{s})$ & 102.5 & \pm 5.8 \\
& \pm SD $(\mathrm{cm} / \mathrm{s})$ & \pm 21.1 & $29.5-58.89$ & $0.015^{*}$ \\
EDV & Range $(\mathrm{cm} / \mathrm{s})$ & $23.97-49.54$ & 39.4 \\
& Mean $(\mathrm{cm} / \mathrm{s})$ & 33.7 & \pm 6.1 \\
& \pm SD $(\mathrm{cm} / \mathrm{s})$ & \pm 7.0 & $0.28-56.8$ \\
RI & Range $(\mathrm{cm} / \mathrm{s})$ & $0.4-0.82$ & 2.8 \\
& Mean $(\mathrm{cm} / \mathrm{s})$ & 0.7 & \pm 10.5 \\
& \pm SD $(\mathrm{cm} / \mathrm{s})$ & \pm 0.1 & $0.32-1.06$ \\
PI & Range $(\mathrm{cm} / \mathrm{s})$ & $0.5-1.4$ & 0.7 \\
& Mean $(\mathrm{cm} / \mathrm{s})$ & 1.0 & \pm 0.2 \\
\hline
\end{tabular}

${ }^{\circ} p$ value $<0.05$ (significant); $P S V$ peak systolic velocity, EDV end diastolic velocity, $P$ pulsatility index, $R I$ resistivity index, SD standard deviation

patients with higher grades of papilledema with a $p$ value 0.001 .

Regarding CSF pressure, the current study findings revealed that there were statistically significant changes in the cerebrovascular hemodynamics before and after CSF withdrawal as follows: PSV pre-CSF withdrawal ranges from 76.5 to 141.12 and post-CSF withdrawal ranges from 56.89 to 112.6 with $p$ value $=0.001$, EDV pre-CSF withdrawal ranges from 23.97 to 49.54 , and post-CSF withdrawal 29.5-58.89 with $p$ value $=0.001$, RI pre-CSF withdrawal ranges from 0.4 to 0.82 and post-CSF withdrawal ranges from 0.28 to 56.8 with ( $p$ value $=0.196$ ), and PI pre-CSF withdrawal ranges from 0.5 to 1.4 and post-CSF withdrawal ranges from 0.32 to 1.06 with ( $p$ value $=0.001)$. These results show significant changes in cerebral hemodynamics associated with a decrease in intracranial pressure.

Different mechanisms to explain the observed changes in the cerebral blood flow in IIH patients were proposed; an increase of the cerebrovascular resistance, impairment of the cerebral blood flow (CBF) autoregulation, and as a result of brain edema, reduction in the tissue vascular density occurs [16].

In harmony with the current study, Aggarwal et al. found changes of PSV-PI-EDV pre- and post-lumbar puncture in a statistically significant fashion with a $p$ value $=0.003$ [17]

When intracranial pressure becomes elevated, an initial compensatory vasodilatation results to maintain CBF. This cerebral blood volume increase was shown to be fully reversible. Other workers have reported dilatation of pia vessels as a response to acute rise in ICP, and brain biopsies of PTC patients have shown distention of the microvasculature network [18].

In this study, measurements specially EDV, PSV, and PI show a significant importance in our results similar to other studies that considered EDV the good and gold standard in measuring accurately the hemodynamics of intracranial pressure [14].

EDV is very important in indicating a low- or highresistance intracranial arterial flow pattern, seen in all major intracranial arteries, and so shows significance in measurements of changes in cerebral perfusion pressure [13].

Those findings are in harmony with previous research studies in which investigators have used a 1-2-day trial of continuous controlled CSF drainage $(10 \mathrm{ml} / \mathrm{h})$ [19]. Response to CSF drainage was defined as improvement in headache symptoms and agreement was also observed by previous investigators' research efforts in which they observed a significant reduction of PI and RI after CSF drainage by lumbar puncture [20].

Other prior research studies have used transcranial Doppler being applied after the first lumbar puncture in all cases and during relapse in 2 cases showing a decrease in PI and RI also after lumbar puncture that support a significant reduction of cerebral blood pressure in agreement with our study [21].

On the other hand, prior research groups examined CBF in patients with IIH before and after reduction of CSF pressure by lumbar puncture and found nonsignificant change, and this study was on 10 patients only, was on papilledema grade one (mild) degree not all grades of papilledema, and use only RI not all parameters of transcranial Doppler [22].

\section{Conclusions}

Intracranial pressure significantly affects cerebral blood flow. A normalization of transcranial Doppler parameters occurs following lowering of intracranial pressure through lumbar puncture. Parameters of transcranial Doppler used in assessing these results were (PSV-EDV-RI-PI). 


\section{Abbreviations}

EDV: End diastolic velocity; ICP: Intracranial pressure; IIH: Idiopathic intracranial hypertension; PI: Pulsatility index; PSV: Peak systolic velocity; RI: Resistivity index; TCCD: Transcranial color-coded duplex; TCD: Transcranial Doppler; CBF: Cerebral blood flow; PTC: Pseudotumor cerebri

\section{Acknowledgements}

Not applicable

\section{Authors' contributions}

MA participated in study design, analysis of data, and helped to draft the manuscript. HA participated in study design, sequence alignment, and helped to draft the manuscript. SA participated in study design, performed the transcranial Doppler work, and helped to draft the manuscript. YG participated in study design, collection of data, and helped to draft the manuscript. MO participated in study design, sequence alignment, and helped to draft the manuscript. All authors read and approved the final manuscript.

\section{Funding}

Authors did not receive any funding for this work.

\section{Availability of data and materials}

The datasets used and/or analyzed during the current study are available from the corresponding author on reasonable request with permission of Faculty of Medicine, Cairo University, Egypt.

\section{Ethics approval and consent to participate}

Written informed consent was obtained from each participant in this study and the study was approved by the authorized research and ethical committee in Faculty of Medicine, Cairo University, in 27 October 2013.

\section{Consent for publication}

Not applicable

\section{Competing interests}

The authors declare that they have no competing interests.

\section{Author details}

${ }^{1}$ Neurology Department, Cairo University, Giza, Egypt. ${ }^{2}$ Neurology

Department, Beni-Suef University, Beni-Suef 62511, Egypt.

Received: 27 December 2019 Accepted: 23 November 2020

Published online: 11 December 2020

\section{References}

1. Binder DK, Horton JC, Lawton MT, McDermott MW. Idiopathic intracranial hypertension. Neurosurgery. 2004;54(3):538-51 discussion 551-2.

2. Friedman DI, Jacobson DM. Diagnostic criteria for idiopathic intracranial hypertension. Neurology. 2002;59(10):1492-5.

3. Alexandrov AV, Joseph M. Transcranial Doppler; an overview of its clinical applications. Internet J Emerg Intensive Care Med. 2000;4:N1.

4. Hunter G, Voll C, Rajput M. Utility of transcranial Doppler in idiopathic intracranial hypertension. Can J Neurol Sci. 2010;37(2):235-9.

5. Bellner J, Romner B, Reinstrup P, Kristiansson K, Ryding E, Brandt L. Transcranial Doppler sonography pulsatility index (PI) reflects intracranial pressure (ICP). Surg Neurol. 2004;62(1):45-51.

6. Gosling RG, King DH. Arterial assessment by Doppler shift ultrasound. Proc R Soc Med. 1974;67:447-9.

7. Kidwell CS, El-Saden S, Livshits Z, Martin NA, Glenn TC, Saver JL. Transcranial Doppler pulsatility indices as a measure of diffuse small-vessel disease. J Neuroimaging, 2001; 11(3): 229-235.

8. Raju T. Cranial Doppler applications in neonatal critical care. Crit Care Clin. 1992;8:93.

9. Raju T. Digre KB, Corbett JJ. Pseudotumor cerebri in men. Arch Neurol. 1988; 45:866-72. [PubMed] [Google Scholar].

10. Smith JL. Whence pseudotumor cerebri? J Clin Neuro Ophthalmol. 1985 5(1):55-6.

11. Frisén L. Swelling of the optic nerve head: a staging scheme. J Neurol Neurosurg Psychiatry. 1982;45:13-8.
12. Wall M, George D. Visual loss in pseudotumor cerebri. Incidence and defects related to visual field strategy. Arch Neurol. 1987:44:170-5.

13. Zweifel C, Czosnyka M, Carrera E, de Riva N, Pickard JD, Smielewski P. Reliability of the blood flow velocity pulsitility index for assessment of intracranial and cerebral perfusion pressures in head-injured patients. Neurosurgery. 2012;71:853-61.

14. Wakerley BR, Sharma VK. Transcranial Doppler derived pulsatility index in the assessment of intracranial pressure: the trend is your friend. Neurosurgery. 2013;72:E319-20.

15. Alexandrov AV. Practical models of cerebral hemodynamics and waveform recognition. In: Alexandrov AV, editor. Cerebrovascular ultrasound in stroke prevention and treatment. Oxford: Wiley-Blackwell; 2011. p. 68-213.

16. Bakar M, Tamgac F, Alper E, Zarifoglu M, Bora I, Turan F, Ogu E. 99TcmHMPAO brain SPET in patients with pseudotumor cerebri. Nucl Med Commun Aug. 1996:17(8):696-700.

17. Aggarwal S, Brooks DM, Kang Y, Linden PK, Patzer JF. Second. Non invasive monitoring of cerebral perfusion pressure. In patients with acute liver failure using transcranial Doppler ultrasonography. Liver Transpl. 2008;14(7):1048-57.

18. Heliopoulos I, Artemis D, Vadikolias K, et al. Association of ultrasonographic parameters with subclinical white-matter hyperintensities in hypertensive patients. Cardiovasc Psychiatry Neurol. 2012;2012:616572. https://doi.org/10. 1155/2012/616572.

19. Torbey M, Ashwani B. Cerebral blood flow physiology and monitoring. Crit Care Neurol Neurosurg. 2004:23-37.

20. Gur AY, Kesler A, Shopin L, Bornstein NM. Transcranial Doppler for evaluation of idiopathic intracranial hypertension. Acta Neurol Scand. 2007; 116(4):239-42.

21. Wakerley B, Yohana $\mathrm{K}$, Luen Teoh $\mathrm{H}$, et al. Non-invasive intracranial pressure monitoring with transcranial Doppler in a patient with progressive cerebral venous sinus thrombosis. J Neuroimaging. 2012. https://doi.org/10.1111/j. 1552-6569.2012.00745.x.

22. Wang $Y$, Duan $Y Y$, Zhou HY, et al. Middle cerebral arterial flow changes on transcranial color and spectral Doppler sonography in patients with increased intracranial pressure. J Ultrasound Med. 2014:33:2131-6.

\section{Publisher's Note}

Springer Nature remains neutral with regard to jurisdictional claims in published maps and institutional affiliations.

\section{Submit your manuscript to a SpringerOpen ${ }^{\circ}$ journal and benefit from:}

- Convenient online submission

- Rigorous peer review

- Open access: articles freely available online

- High visibility within the field

- Retaining the copyright to your article

Submit your next manuscript at $\boldsymbol{\nabla}$ springeropen.com 